\section{The Bromodomain testis-spe- cific gene (Brdt) characteriza- tion and expression in gilthead seabream, Sparus aurata, and European seabass, Dicentrarchus labrax}

\author{
M. Úbeda-Manzanaro, \\ J.B. Ortiz-Delgado, C. Sarasquete
}

Institute of Marine Science of Andalusia (ICMAN.CSIC), Campus Universitario Rio

San Pedro, Puerto Real, Cadiz, Spain

\section{Abstract}

Multiple genes and transcription factors are involved in regulation and control of the complex process of sex determination and differentiation of fish species. Also more, several hormonal factors and some environmental conditions can also be adequate spawning strategies and stimuli for inducing reproduction of fish species. Brdt gene belongs to the bromodomain-extraterminal domain (BET) family of transcriptional coregulators. In mammals, Brdt gene is almost exclusively expressed in testis. Furthermore, Brdt protein is involved in elongating spermatids, and is required for proper spermatogenesis and male fertility. However, from our understanding of fish species, the role of this gene as key, during gametogenesis, still remains unknown. In this study, two Brdt mRNA transcripts were isolated from two teleostean fish species, gilthead seabream and European seabass. In both species the shorter form lacked a functional Cterminal domain, which may involve a different function as transcriptional regulator. The pattern of Brdt expression showed that the highest levels occurred in the gonads. Significantly lower levels of expression were detected in brain, pituitary and different organ systems (heart, kidney, gills, among other somatic tissues) from both studied species. In situ hybridization approach evidenced that Brdt mRNA expression was restricted to specific cell-types of the germ line, during both oogenesis and spermatogenesis processes.

\section{Introduction}

The gilthead seabream (Sparus aurata) and the European seabass (Dicentrarchus labrax) are two fish species currently farmed on a large scale. These marine teleostean species are common throughout the Mediterranean and are also found along the Eastern Atlantic coasts. ${ }^{1,2}$ In aquaculture systems, understanding and control of reproduction is needed for synchronous and reliable maturation and spawning. ${ }^{3}$ Although the basic mechanisms of reproduction of both fish species have been extensively studied, ${ }^{4,5}$ application of genetic, molecular and cellular markers will allow for advancement in the understanding of the molecular mechanisms that can be involved in the genetic regulation of the reproductive process in fish. There are multiple genes and transcription factors (cyp19a, amh, vasa, dmrt, etc.) involved in the regulation and control of sex determination-differentiation and gametogenesis in fish species. ${ }^{6,7}$ Currently, other genes are analyzed for their involvement in cell proliferation process, such as the Bromodomain testis-specific (Brdt) gene, which in mammals regulates spermatogenesis and it is particularly important for male fertility. ${ }^{8}$ However, from our understanding, there are no studies of Brdt gene in fish.

The Brdt gene encodes a protein member of the bromodomain and extra terminal (BET) protein family. ${ }^{9}$ The BET proteins are characterized by two $\mathrm{N}$-terminal bromodomains that bind to acetylated histone tails, with the exception of plant BETs which contain a single bromodomain. ${ }^{10}$ BETs also have an extra-terminal motif (ET) in the C-terminal region, often followed by a SEED motif which contains polyserine residues interspersed with aspartic and glutamic acids. ${ }^{11}$ Members of the BET family of proteins are usually well conserved in many species from yeast to human, ${ }^{11}$ and they seem to play an important role in the modulation of gene expression by epigenetic mechanisms, which regulate genome reprogramming during gametogenesis, early embryogenesis, cell differentiation, and maintenance of lineage commitment. ${ }^{12}$

In mammals, there are four BET genes: $\mathrm{Brd} 2, \mathrm{Brd} 3, \mathrm{Brd4}$, and $\mathrm{Brdt}$, which are differentially expressed during spermatogenesis, ${ }^{8}$ and particularly, only Brdt is almost exclusively expressed in the testis. ${ }^{13,14}$ The Brdt protein is an essential factor for proper spermatogenesis and for male fertility. Indeed, homozygous mice for a mutation $B r d t^{D B D I / D B D 1}$ lacking the first bromodomain (BD1) of Brdt presented severe reduction in the spermatozoa number, and decreased motility and high abnormalities in the sperm, and $B r d t^{D B D I / D B D I}$ spermatids failed to elongate properly. ${ }^{15,16}$ It has also been reported that BD1 was involved in chromocenter formation and maintenance, showing multiple heterochromatic foci in spermatids of $B r d t^{D B D I D B D I}$ mutant mice instead of a single focus as was established in round spermatids of wild-type mice. ${ }^{15}$

Brdt protein acts as a transcriptional regulator, binding histone H4-diacetylated in K5 and
Correspondence: Dr. María Úbeda-Manzanaro, Institute of Marine Science of Andalusia (ICMAN.CSIC), Campus Universitario Rio San Pedro, 11519 Puerto Real, Cadiz, Spain.

Tel. +34.956 .832612 . Fax: +34.956 .834701 .

E-mail: mariaubeda.manzanaro@icman.csic.es

Key words: Brdt; gene expression; in situ hybridization; oogenesis; spermatogenesis; seabream; seabass.

Contributions: JBOD, CS, study conception, participation in the experimental design; MUM, performing of experimental technical part and statistical analysis, manuscript writing. All authors have participated actively in the study and approved the final manuscript.

Conflict of interest: the authors declare no conflict of interest.

Acknowledgments: the authors are grateful to $\mathrm{Mr}$. Juan Canales for technical assistance in this work, and to Dr. Martínez-Rodríguez for helping in some molecular technique-optimization.

Funding: this study was supported by funding of CSIC (Project-Germfish 2014-2015, and AGL201452906R; Spain).

Received for publication: 16 February 2016. Accepted for publication: 12 April 2016.

This work is licensed under a Creative Commons Attribution-NonCommercial 4.0 International License (CC BY-NC 4.0).

(C) Copyright M. Úbeda-Manzanaro et al., 2016 Licensee PAGEPress, Italy

European Journal of Histochemistry 2016; 60:2638 doi:10.4081/ejh.2016.2638

K8 by BD $1,{ }^{17}$ and it has been demonstrated that round spermatids of $B r d t^{D B D I / D B D 1}$ mutant mice suffer a significant alteration in transcription of genes in comparison to normal mice. ${ }^{18} \mathrm{Brdt}$ also plays an important role in post-transcriptional processing during spermatogenesis, interacting with several spliceosome components for mRNA splicing in the testis, and it is involved in 3'-UTR processing in round spermatids. ${ }^{18}$

It is known that Brdt protein is required for the completion of meiosis I, since it is expressed from the pachytene to diplotene stages of spermatocytes in mice, acting as a transcriptional regulator. ${ }^{19}$ However, $B r d t^{D B D I / D B D 1}$ mutant mice completed meiosis successfully, ${ }^{16}$ so it is thought that other domains but not BD1, possess an important role in meiosis. In this sense, only mutations in the second bromodomain (BD2) of the yeast BET gene Bdfl failed to sporulate, so it is thought that BD2 may be the key to completion 
of meiosis. ${ }^{20}$

Brdt protein also shows the capacity for remodeling and compacting chromatin after induction of histone hyperacetylation during the critical post-meiotic stages of spermatogenesis. ${ }^{13}$ Gaucher et al. ${ }^{19}$ suggested that Brdt has a potential role in the replacement of hyperacetylated histones by transition nuclear proteins, which are later replaced by protamines to genome condensation during the elongation of spermatids. ${ }^{21}$

In this novel study we report, for the first time in two marine fish species, the identification, molecular cloning and characterization of Brdt in gilthead seabream (Sparus aurata) and European seabass (Dicentrarchus labrax). A first molecular and cellular approach was performed using quantitative and qualitative methods (qPCR and in situ hybridization techniques, respectively) to determinate the gene expression patterns in different organ systems (gonads, brain, hypophysis, heart, kidney, spleen among other somatic tissues).

\section{Materials and Methods}

\section{Biological samples}

All specimens of gilthead seabream ( $S$. aurata) and European seabass (D. labrax) used in this study were cultured in the facilities of the Institute of Marine Sciences of Andalusia (ICMAN.CSIC, Puerto Real, Spain). These aquaculture facilities were approved for animal experimentation (certificate number REGA-ES110280000311) in accordance with Spanish legislation (R.D. 53/2013) and the experimental protocol was approved by the Spanish National Research Council (CSIC) Ethics Committee from project CSIC-Germfish 2014-2015. Deep anesthesia was induced with 1500 ppm phenoxyethanol (Sigma-Aldrich, St. Louis, M0, USA) and six adult fish of each species were slaughtered by decapitation. Samples of different organ systems and tissues (gill, intestine, rectum, anterior kidney, posterior kidney, heart, spleen, liver, brain, muscle, ovary, testis, and hypophysis, plus stomach only in European seabass) were collected into RNAlater $^{\circledR}$ (Sigma-Aldrich), incubated for $24 \mathrm{~h}$ at $4^{\circ} \mathrm{C}$ and stored at $-20^{\circ} \mathrm{C}$ until RNA extraction (within two weeks). For in situ hybridization (ISH), gonads were sampled and fixed with $4 \%$ paraformaldehyde in diethylpyrocarbonate (DEPC) treated phosphate-buffered saline (PBS) and then processed according to ÚbedaManzanaro et al.22

\section{Nucleic acids extraction}

Total RNA from hypophysis was extracted using the NucleoSpin ${ }^{\circledR}$ RNA XS kit (MacheryNagel), whereas total RNA from other organs and tissues was isolated using NucleoSpin ${ }^{\circledR}$ RNA II kit (Macherey-Nagel) according to the manufacturer's protocol. Total RNA concentration was assessed by spectrophotometry (A260 nm/A280 nm ratio >1.8) and integrity verified with a Bioanalyzer 2100 and with the RNA 6000 Nano kit (Agilent Technologies).

\section{Cloning and phylogenetic analysis}

Testis and ovary cDNA templates were synthesized from $1 \mu \mathrm{g}$ total RNA using the SMARTer ${ }^{\mathrm{TM}}$ RACE cDNA Amplification kit (Clontech) according to the manufacturer's instructions. Firstly, this cDNA was used to perform a PCR with degenerated pair of

Table 1. Primers used for the sequencing and quantification of Brdt mRNA levels in Sparus aurata (prefix Sa-) and Dicentrarchus labrax (prefix Dl-).

\begin{tabular}{|c|c|c|c|c|}
\hline Primer & Sequence $\left(5^{\prime} \rightarrow 3^{\prime}\right)$ & Application & $\mathbf{R}^{2}$ & $\mathbf{E}$ \\
\hline Brdt-degF & CCYGGGGATGAYATTGTTYTKATGGC & Obtaining a partial specific sequence & & \\
\hline Brdt-degR & CCMAGTTTGTCWCCAGGMAGCTTGTT & Obtaining a partial specific sequence & & \\
\hline Sa-Brdt-1345F & GAGGCAGAGGGTACATCAGAGGTGGTGGCC & 3'-RACE & & \\
\hline Sa-Brdt-1617F & GCTCGCATCAATTCCAGTGACT & 3 nested & & \\
\hline Sa-Brdt-1809F & GAGGTTTGTTGCAGCATGTC & 3 nested & & \\
\hline Sa-Brdt-1401R & CCGCTCCTTCAGATCCGCAAGCTGTGTGGC & 5'-RACE & & \\
\hline Sa-Brdt- 526F & CAATTGCCGAAGGAAGAGTTTGA & In situ hybridization & & \\
\hline Sa-Brdt-696R & TCAATTTGTGCTGAGAGCTGG & In situ hybridization & & \\
\hline Sa-Brdt-874F & AAAGACTTGCCGACCTTTGA & $\mathrm{qPCR}$ & 0.9992 & 1.9992 \\
\hline Sa-Brdt-985R & GCCAGGCGTATGGATAGTGT & & & \\
\hline Sa-18S-F & AACCAGACAAATCGCTCCAC & qPCR & 0.9998 & 1.9817 \\
\hline Sa-18S-R & CCTGCGGCTTAATTTGACTC & & & \\
\hline Sa-Beta actin-F & TCTTCCAGCCATCCTTCCTCG & qPCR & 0.9995 & 2.0110 \\
\hline Sa-Beta actin-R & TGTTGGCATACAGGTCCTTACGG & & & \\
\hline Dl-Brdt-1607F & GGTCCAATCAATACCAGTGACC & 3'-RACE & & \\
\hline Dl-Brdt-1354R & AGCTGTGAGGCCACCTCTTCGGATGAAACTC & 5'-RACE & & \\
\hline Dl-Brdt-691R & TCAATTTGTGCAGAGAGCTGG & 5 nested \& in situ hybridization & & \\
\hline Dl-Brdt-501F & CAAATGCCTAAGGAAGAGTGTGA & In situ hybridization & & \\
\hline Dl-Brdt-2265F & GAAACCAAAGGGCTCCCAAC & qPCR & 0.9968 & 1.9873 \\
\hline Dl-Brdt-2392R & GCAGCCCAGTCCAGTGAAAC & & & \\
\hline Dl-L13a-F & TCTGGAGGACTGTCAGGGGCA & qPCR & 0.9987 & 2.0006 \\
\hline Dl-L13a-R & AGACGCACAATCTTGAGAGCAG & & & \\
\hline Dl-Beta actin-F & CAGGGAGAAGATGACCCAGA & qPCR & 0.9994 & 1.9823 \\
\hline Dl-Beta actin-R & CCGGAGTCCATGACAATACC & & & \\
\hline
\end{tabular}

$100 \%$ efficiency is $\mathrm{E}=2$ (slope -3.32 ). To accept the standard curve the $\mathrm{R}^{2}$ value must be $>0.99 . \mathrm{K}=\mathrm{G} / \mathrm{T} ; \mathrm{M}=\mathrm{A} / \mathrm{C} ; \mathrm{W}=\mathrm{A} / \mathrm{T} ; \mathrm{Y}=\mathrm{C} / \mathrm{T}$ 
primers Brdt-degF/Brdt-degR (Table 1) to amplified specific partial sequences from $B r d t$ of both fish species. These primers were designed from sequence alignment of teleost fish orthologs using ClustalW (http://www. genome.jp/tools/clustalw/) and FastPCR 6.0. ${ }^{23}$ PCRs were carried out in a Doppio thermocycler (VWR) using a total volume of $50 \mu \mathrm{L}$ containing $2 \mu \mathrm{L}$ of 5'-RACE-Ready cDNA, $5 \mu \mathrm{L}$ complete reaction buffer $(10 \mathrm{x}), 400 \mu \mathrm{M}$ of dNTP mix, $200 \mathrm{pM}$ of each primer, and $2.5 \mathrm{U}$ of DFSTaq DNA polymerase (Bioron). Thermocycler conditions were $1 \mathrm{~min}$ at $94^{\circ} \mathrm{C}$, followed by 35 cycles of $30 \mathrm{~s}$ at $94^{\circ} \mathrm{C}, 30 \mathrm{~s}$ at $56^{\circ} \mathrm{C}$, and $1.5 \mathrm{~min}$ at $72^{\circ} \mathrm{C}$, and a final $7 \mathrm{~min}$ extension at $72^{\circ} \mathrm{C}$. The PCR products were purified and inserted into pGEM $^{\circledR}$-T Easy Vector System (Promega). The positive clones were sequenced at the Sequencing Service from Biomedal (Seville, Spain).

Secondly, gene specific primers (saBrdt1345F, saBrdt-1401R, dlBrdt-1607F, dlBrdt 1354R, saBrdt-1617F, saBrdt-1809F, and dlBrdt$691 \mathrm{R}$, Table 1) were designed using the obtained Brdt partial sequences for performing 3'- or 5'-RACE-PCR and nested reactions, and obtaining the full-length sequences of $B r d t$ cDNA. The RACE-PCR reactions were performed according to the manufacturer's manual, adapting the annealing temperature to the corresponding primer. The obtained sequences were assembled in a single one using BioEdit 7.0.9.0. ${ }^{24}$

The Brdt sequences of gilthead seabream and European seabass were translated into amino acids using a translate tool (http://web.expasy.org/translate/) and a phylogenetic reconstruction was performed using the neighbor-joining method ${ }^{25}$ with MEGA 6 software, ${ }^{26}$ after a multi-alignment of selected BET-family proteins with ClustalW algorithm. Bootstrap resampling method ${ }^{27}$ was applied to assess support for individual nodes using 10,000 replicates, and the evolutionary distances were computed using the Poisson correction method, ${ }^{28}$ uniform rates among sites, and pairwise deletion option treatment of gaps and missing data.

\section{Expression analysis: real-time qPCR}

Total RNA ( $\approx 500 \mathrm{ng}$ ) was reverse-transcribed using qScript ${ }^{\mathrm{TM}}$ cDNA Synthesis kit (Quanta BioSciences, Gaithersburg, MD, USA) according to the manufacturer's protocol.

For the relative quantification of gene expression using real-time PCR (qPCR) of $B r d t$ genes, specific primer pairs (Table 1) were finally designed at a common region to both transcripts of each species, since the sequence of the short transcript (saBrdt-b or $d l B r d t-b)$ differs from the long transcript (saBrdt-a or $d l B r d t-a$, respectively) in only about $200 \mathrm{bp}$, which limited the design of specific primers for the short isoform. qPCR reactions were performed on a Mastercycler ${ }^{\circledR}$ ep gradient S Realplex ${ }^{2}$ with Realplex software version 2.2 (Eppendorf). Reactions were performed in a final volume of $10 \mu \mathrm{L}$ with $400 \mathrm{nM}$ of each primer, $4 \mu \mathrm{L}$ of a 1/10 dilution of cDNA $(\approx 10 \mathrm{ng})$, and $5 \mu \mathrm{L}$ PerfeCTa ${ }^{\mathrm{TM}} \mathrm{SYBR}^{\circledR}$ Green FastMix $^{\mathrm{TM}}$ (Quanta BioSciences). qPCR was run with the following parameters: $95^{\circ} \mathrm{C}$ for 2 min, 40 cycles at $95^{\circ} \mathrm{C}$ for $15 \mathrm{~s}, 56^{\circ} \mathrm{C}$ for $S$. aurata genes or $60^{\circ} \mathrm{C}$ for D. labrax genes for 15 $\mathrm{s}$, and $60^{\circ} \mathrm{C}$ for $15 \mathrm{~s}$. All primers gave single distinctive melting peaks, demonstrating that no primer dimmers and unspecific amplification products were present. The real-time PCR efficiencies were calculated from the slope, according to the equation $\mathrm{E}=10^{[-1 / \text { slope }}$. Relative gene quantification was performed using the method of Pfaffl, ${ }^{29}$ using $\beta$-actin (primers from Mohammed-Geba et $a l^{30}$ ) and 18S rRNA (Martos-Sitcha et al. ${ }^{31}$ ) as the internal control genes for $S$. aurata or $\beta$-actin [GenBank: AJ537421.1] and L13a (Mitter et al. ${ }^{32}$ ) for $D$. labrax, with mRNA from the lowest expression level as calibrator (gills in the case of $S$. aurata, or liver for D. labrax). Three biological replicates of each sample were analyzed and each PCR was performed in parallel with a technical duplicate. Negative qPCR controls using double-distilled water and RNA instead of cDNA were included in the assays for each primer pair.

\section{Statistical analysis}

The normality of data was checked with the Shapiro-Wilk's test and the homoscedasticity of variance with the Levene's test. Differences in tissue distribution for Brdt expression were evaluated by one-way analysis of variance (ANOVA) performed after logarithmic base 10 transformation. Pairwise comparisons were performed by the Student-Newman-Keuls (SNK) post-hoc test. Differences were considered statistically significant at $\mathrm{P}<0.05$. Statistical analyses of data from qPCR were performed using SPSS 23.0.0.0 software (IBM).

\section{In situ hybridization}

The Brdt riboprobes for both fish species were generated from a $191 \mathrm{nt}$ fragment from a region located between the first bromodomain and the motif A (primers in Table 1). Digoxigenin (DIG)-labeled antisense and sense riboprobes were synthesized by in vitro transcription with the DIG RNA labeling Kit (SP6/T7) according to the manufacturer's instructions (Roche Diagnostics, Basel, Switzerland). In situ hybridizations were performed according to Úbeda-Manzanaro et al. ${ }^{22}$ on histological section of testes and ovaries. Sections were rehydrated and permeabilized for $15 \mathrm{~min}$ in $10 \mu \mathrm{g} / \mathrm{mL}$ proteinase $\mathrm{K}$ in phosphate buffered saline with Tween 20 (PBST: $137 \mathrm{mM} \mathrm{NaCl}, 2.7 \mathrm{mM} \mathrm{KCl}, 1.8 \mathrm{mM} \mathrm{KH}_{2} \mathrm{PO}_{4}, 10$ $\mathrm{mM} \mathrm{Na} \mathrm{HPO}_{4}, 0.1 \%$ Tween-20) at $37^{\circ} \mathrm{C}$. After postfixation in $4 \%$ paraformaldehyde-PBST for 30 min, sections were incubated for $2 \mathrm{x} 15 \mathrm{~min}$ in PBST containing $0.1 \%$ active DEPC, and equilibrated for 15 min in PBST. The histological sections were then pre-hybridized for $2 \mathrm{~h}$ at $57^{\circ} \mathrm{C}$ in the hybridization mix, and later, they were hybridized with the sense or antisense probes at $57^{\circ} \mathrm{C}$ overnight in a humidified chamber. After incubation, the sections were washed three times in $2 \mathrm{x} \mathrm{SSC}$ at $52^{\circ} \mathrm{C}$ for 30 min, later they were washed twice at $52^{\circ} \mathrm{C}$ with $1.4 \mathrm{xSSC} / 0.6 \%$ CHAPS (3-[3-cholamidopropyl)dimethylamonio]1-propanesulfonate, and once with 1:1 PTW: maleic acid buffer $(0.1 \mathrm{M}$ maleic acid, $0.15 \mathrm{M} \mathrm{NaCl}, \mathrm{pH} 7.5)$. Detection of the hybridized probe was carried out using alkaline phosphatase-coupled anti-digoxigenin antibody, and the hybridization signals were detected by NBT/BCIP system according to the manufacturer's instructions (Roche), adding $5 \mathrm{mM}$ levamisole (Sigma-Aldrich) to neutralize the high endogenous alkaline phosphatase activity previously detected in gonad samples and particularly in ovaries of both species.

\section{Results}

\section{Isolation and characterization of Brdt cDNA and phylogenetic analysis}

Two full-length Brdt cDNAs from gonads of $S$. aurata were obtained using degenerated RTPCR and 3'- and 5'-RACE, and the two transcripts were designated as saBrdt- $a$ and $s a B r d t-b$. The saBrdt- $a$ [GenBank: KT734775] is the longest transcript (3,957 nt), and consisted of 132 nt 5 '-UTR (untranslated region), an open reading frame (ORF) of 2,937 nt (corresponding to 978 deduced amino acids), and a 3'-UTR of 861 nt with a poly (A) tail. The $s a B r d t-b$ [GenBank: KT734778] is the shortest transcript (2,347 nt), showing an ORF of 1,989 nt (662 aa), followed by a shorter 3'-UTR of 198 nt ending in a poly (A) tail. Similarly, we also described two full-length Brdt cDNAs from testis of $D$. labrax: a longer transcript called $d l B r d t-a$, and a shorter one named dlBrdt- $b$. The $d l B r d t-a$ transcript [GenBank: KT734772] is $3982 \mathrm{nt}$, with a 5'-UTR of $107 \mathrm{nt}$, an ORF of $2940 \mathrm{nt}$ (979 aa), and a 3'-UTR of 911 nt with a poly (A) tail. The dlBrdt-b [Genbank: KT734773] is $2309 \mathrm{nt}$, with an ORF of $1995 \mathrm{nt}$ (678 aa) and a 176 nt 3'-UTR with its poly (A) tail. Both Brdt- $a$ and Brdt- $b$ transcripts of both fish species differ in the 3 '-UTR sequence and the 3'- end of the coding sequence. Figure 1 
shows the putative protein sequences of these transcripts and the conserved motifs.

The phylogenetic tree analysis constructed with amino acid sequences for BET protein family (Figure 2) showed a strong evolutionary conservation of BET sub-family of proteins in fish. Both Brdt protein sequences from gilthead seabream and European seabass were clustered in the Brdt subfamily, with the other Brdt homologues from fish species of the order Perciformes.

\section{Brdt mRNA expression analysis}

The Brdt expression patterns in both fish species were analyzed by qPCR showing relative expression levels in all tested organ systems and tissues from adult specimens, particularly in gonads. In this study, qPCR was not performed taking into account the two different transcripts, because the differences between short and long forms were less of 200 bp, so the design of a primer pair for the short transcript was limited. For gilthead seabream, higher statistically significant expression levels were detected in the testis, followed by the ovary; moderate levels of Brdt mRNA expression were observed in the brain and muscle, whereas in the other organs and tissues analyzed, Brdt mRNA expression levels were lower (Figure 3A). Nevertheless in European seabass, the highest expression levels were similarly detected in ovary and testis, moderate expression level was observed in the brain, and very low levels of $B r d t$ mRNA expression were detected in the rest of the organs and tissues (Figure 3B).

Spatial Brdt mRNA tissue expression was analyzed by using specific sense and antisense RNA probes for in situ hybridization approach on ovarian and testicular histological sections of $S$. aurata and D. labrax adult specimens. In testis of gilthead seabream, Brdt mRNA is specifically expressed in secondary spermatocyte cysts and in spermatids, whereas in the ovary the Brdt mRNA was expressed in the cytoplasm of late previtellogenic oocytes, and a weak in situ hybridization signal was detected in early vitellogenic oocytes. No hybridization signals were detected in primary spermatocyte cysts, spermatozoa, early previtellogenic oocytes and advanced vitellogenic oocytes from S. aurata (Figure $4 \mathrm{~A}, \mathrm{~B})$. In European seabass, the Brdt mRNA expression in the ovary was restricted to cytoplasm of late previtellogenic oocytes, and in testis, in situ hybridization signals were detected in spermatids. No hybridization signals were detected in spermatozoa, spermatogonia, early previtellogenic and vitellogenic oocytes from the European seabass gonads (Figure 4 C-E).

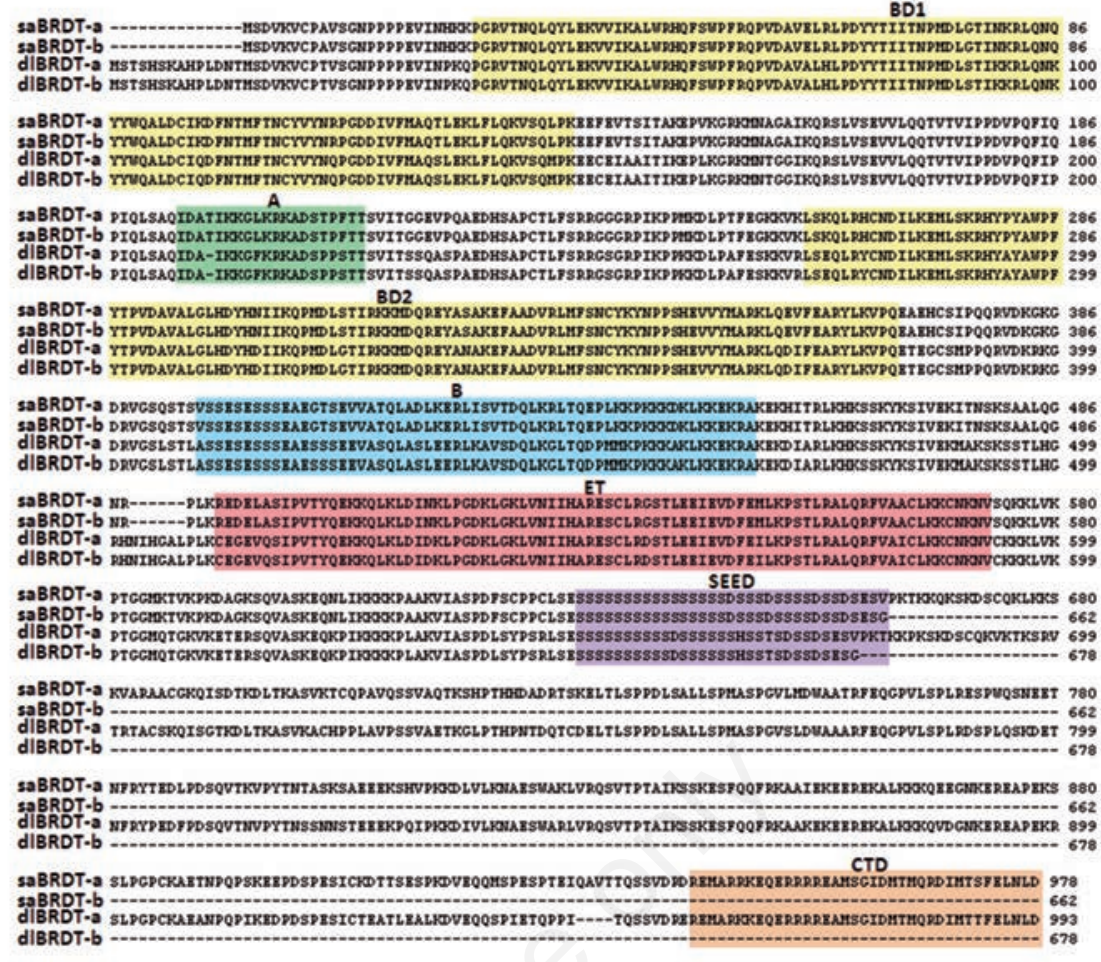

Figure 1. Amino acid sequence alignment of the Brdt transcripts from gilthead sebream and European seabass. The bromodomains 1 and 2 are shaded in yellow, the A motif in green, the B motif in blue, the ET motif in red, the SEED motif in purple, and CTD motif is shaded in orange. Number on the right denotes the amino acid position. Dashed line (--) indicate gaps inserted for improved alignment.

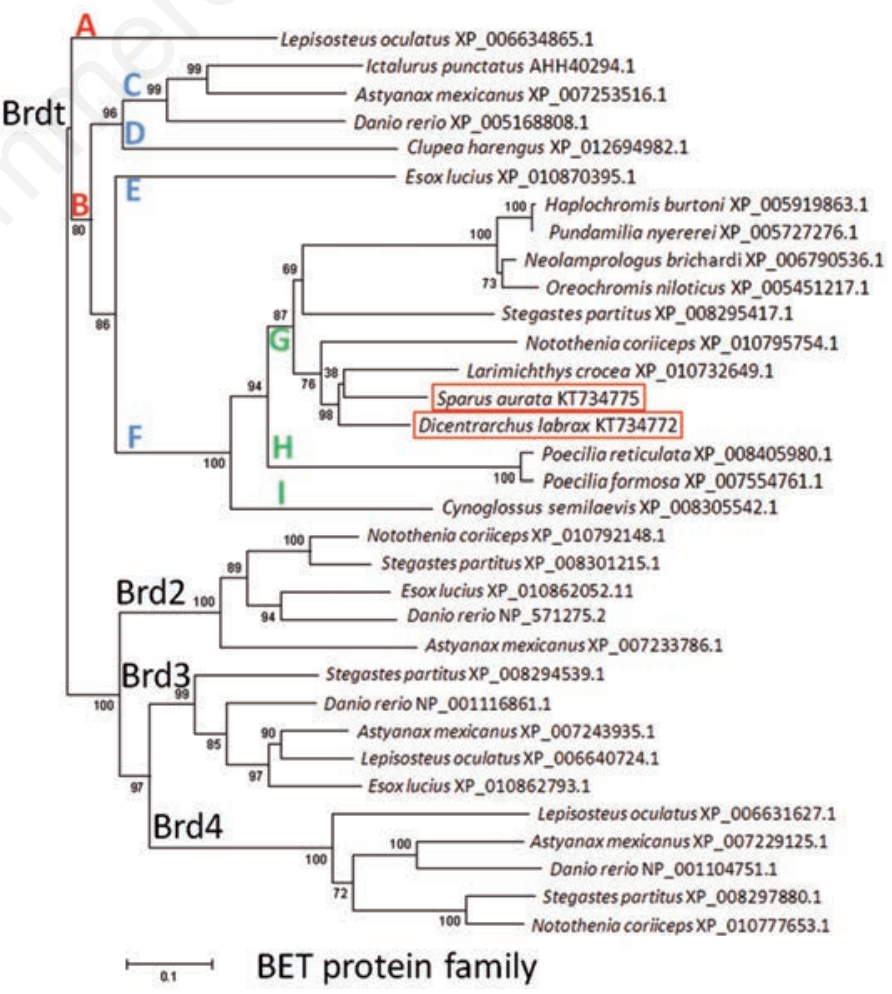

Figure 2. Phylogenetic tree of fish BET proteins using the neighbor-joining method with MEGA 6.06. The Genbank accession numbers of the sequences used are written beside the name of the fish species. Infraclass: Holostei (A), Teleostei (B). Superorders: Ostariophysi (C), Clupeomorpha (D), Protacanthopterygii (E), Acanthopterygii (F). Orders: Perciformes (G), Cyprinodontiformes (H), Pleuronectiformes (I), Beloniformes (J). 


\section{Discussion}

This is the first study designed to understand the expression of the Brdt gene during gametogenesis of fish species and to assess the utility of $B r d t$ mRNA expression as a marker for the presence of germ line cells in testes, as was largely pointed out for mammals. This study shows that in both gilthead seabream and European seabass species Brdt genes express two transcripts which encode proteins differing at their functional C-terminal end, which may suggest that the short Brdt transcript has a different function from the long Brdt form as a transcriptional regulator. Mammalian BET proteins show a conserved organization of their domains, which is also observed in homologues from other organisms like Drosophila Fsh and Saccaromyces cerevisiae Bdf1 and Bdf2 proteins.33 The putative amino acid sequences of the transcripts described in $S$. aurata and D. labrax contain the characteristic domains of the BET protein family: BD1, BD2 and the ET domain. Other regions such as motifs $B$ and SEED are also highly conserved, and to a lesser extent the A motif. ${ }^{34}$ Brdt contains a CTD (C-terminal domain) which is not present in $B r d 2$ and $B r d 3$, making it structurally similar to $B r d 4$ and to the long isoform of Drosophila female sterile homeotic $[F s(1) h L] .^{11,33}$ However, $s a B r d t-b$ and $d l B r d t-b$ transcripts from seabream and seabass fish specimens, respectively, encode a truncated protein product lacking CTD, which is comparable to short isoforms of $b r d 4$ and $f s(1) h .{ }^{11,33}$ A similar short Brdt mRNA transcript lacking CTD has not been reported in humans or mice, although diverse isoforms of the Brdt generated by alternative splicing have been reported in Drosophila, mouse and human..$^{9,13,35}$ BET proteins containing CTD, such as Brd4, Brdt and Fs(1)hL specifically interact with positive transcription elongation factor b (P-TEFb) in mammalian cells by their C-terminal domains. ${ }^{36}$ Therefore, Brdt is the unique BET protein that would be able to perform P-TEFb-mediated transcriptional regulation in spermatocytes or spermatids, ${ }^{19}$ considering that Brd4 was not expressed in these cells in mice. ${ }^{14}$

Paillisson et al.34 suggested that Brdt sequence is the least conserved among mammalian BET protein family because a phylogenetic analysis performed with five species of mammals showed that Brdt presents the highest evolutionary rate in comparison with Brd2, Brd3, and Brd4. The phylogenetic analysis performed with BET proteins from different fish species (Figure 2) also supports the hypothesis that Brdt evolves faster than other BET paralogs. In mammals, Brdt protein has a known role in germ cell differentiation, ${ }^{16,19}$ and it has
A

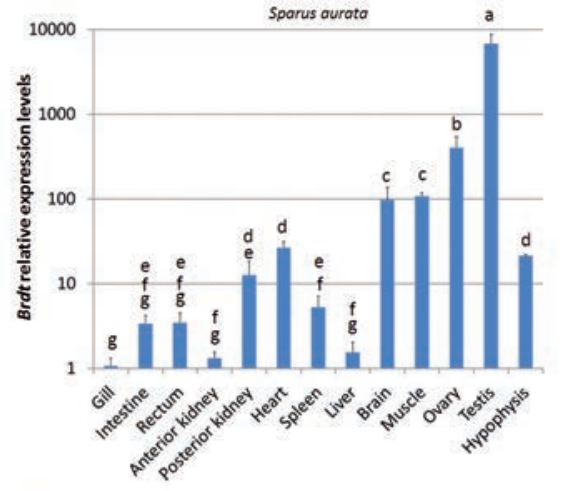

B

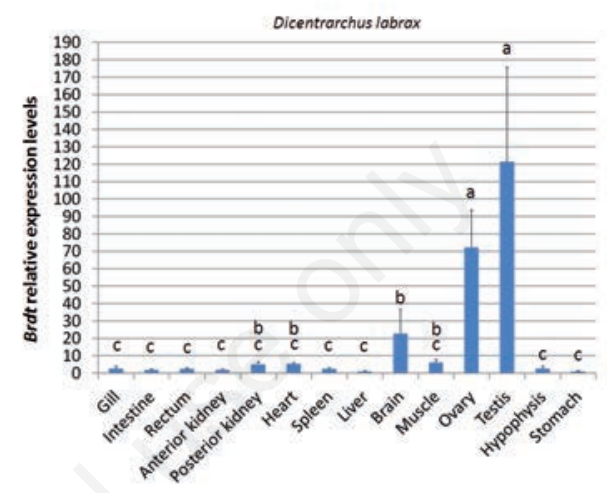

Figure 3. Relative expression profile of $B r d t$ mRNA in adult gilthead seabream tissues (A), and in adult European seabass tissues (B). Small case letters (a-g) indicate statistically significant differences detected by ANOVA, SNK post-hoc test, $\mathrm{P}<0.05$ (mean \pm SEM, $\mathbf{n}=3)$.
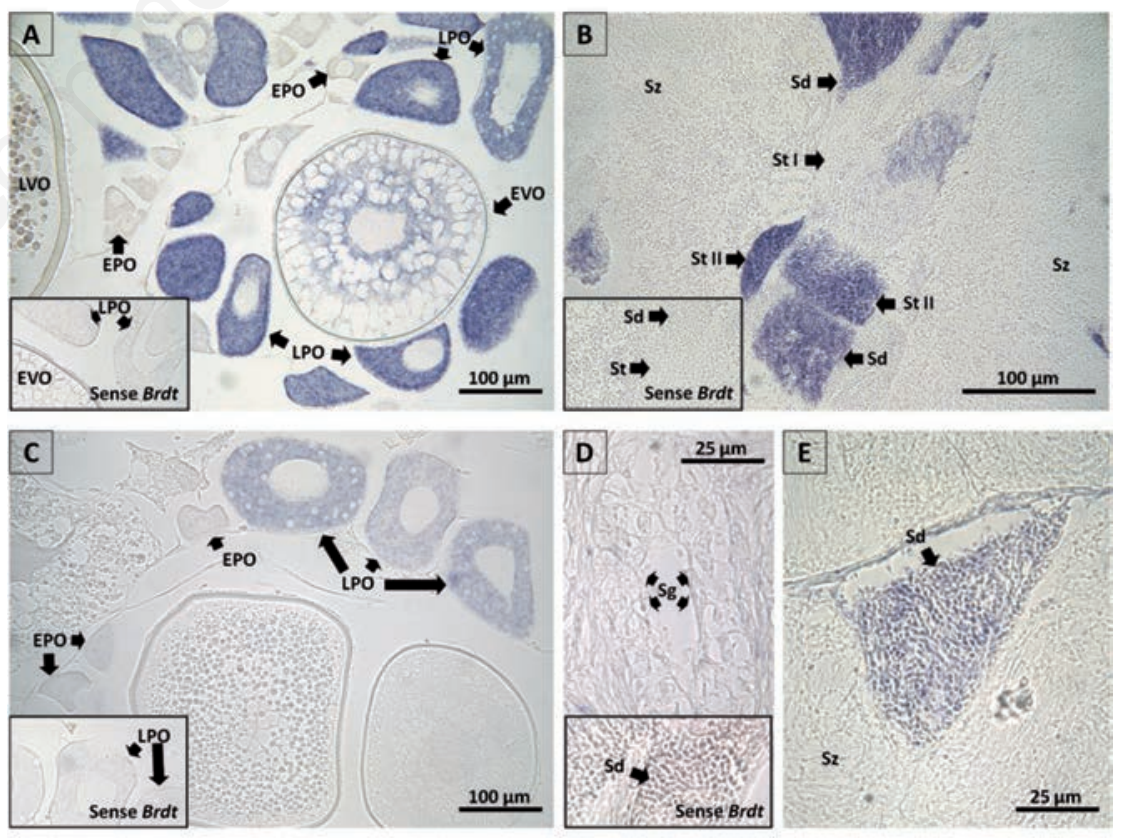

Figure 4. In situ hybridization analysis of Brdt mRNA expression in gonadal sections. A) Gilthead seabream ovary. B) Gilthead seabream testis. C) European seabass ovarian. D,E) European seabass testis. Sense probe controls in ovary and testis are included in the lower left corner of panels A, B, C, and D, respectively, with the same scale as for antisense riboprobe pictures. EPO, early previtellogenic oocytes; EVO, early vitellogenic oocytes; LPO, late previtellogenic oocytes; LVO, late vitellogenic oocytes; StI, primary spermatocyte cysts; StII, secondary spermatocyte cysts; Sd, spermatids; Sg, spermatogonia; Sz, spermatozoa. 
been demonstrated that genes involved in sex determination-differentiation and reproduction events evolve faster than genes expressed in somatic tissues. ${ }^{37}$

In mammals, Brdt gene is almost exclusively expressed in the testis, ${ }^{9,13,14,38}$ although some authors have also reported low expression levels in oocytes ${ }^{34}$ and in the brain ${ }^{14}$ of mice. This controversy in the Brdt expression patterns of mice may be due to the application of different methodology, using techniques of distinct sensitivity, such as northern-blot, reverse transcriptase-PCR, and ISH. The tissue expression profiles of the Brdt genes from gilthead seabream and European seabass were performed by qPCR. In both species, Brdt mRNA expression levels have been detected in many organ systems and tissues showing weak levels of expression, with some exceptions such as gonads or the brain. In $S$. aurata the highest expression level was observed in testis, whereas Brdt expression level in the ovary was high but statistically lower than in testis. In $D$. labrax the highest Brdt mRNA expression levels were reported in both ovary and testis, without statistical differences.

According to Shang et $a l .^{14}$, in mice, Brdt mRNA was expressed at meiotic prophase of spermatocytes, especially at the pachytene stages, although Brdt protein was evidenced in several stages from pachytene and diplotene spermatocytes, and in the round spermatids. ${ }^{16}$ Human Brdt protein was located in spermatocytes up to ejaculated spermatozoa, suggesting that there may be some interespecific differences in the functions of Brdt genes. ${ }^{39}$ Our results confirm the Brdt mRNA expression in one type of spermatocyte cysts, suggesting that $B r d t$ also plays a role in completion of meiosis I during fish spermatogenesis. We also reported Brdt expression in spermatids, which may be associated with the Brdt function in genome condensation or as a transcriptional regulator during this spermatogenic developmental stage. As it is largely known, the Brdt protein has two $\mathrm{N}$-terminal bromodomains that bind to acetylated histone tails. ${ }^{10}$ Interestingly, Kurtz et al. ${ }^{40}$ reported that $\mathrm{H} 4$ histone acetylation occurs during spermiogenesis of both $S$. aurata and $D$. labrax, but in the first fish species ( $S$. aurata) there was no displacement of histones by protamines or any other sperm nuclear basic proteins, whereas in the second fish species (D. labrax) the histone substitution by protamines during spermiogenesis was reported. These differences observed in the expression of Brdt gene between both studied fish species, could suggest a different role of Brdt protein during spermatogenesis as a transcription regulator and/or remodeling and compacting the chromatin depending on each species. ${ }^{17,19}$

In situ hybridization approach performed on ovarian histological sections from both $S$. aurata and D. labrax confirmed that Brdt mRNA is specifically expressed in oocytes, similar to results previously reported in mice oocytes. ${ }^{34}$ However, the Brdt expression pattern observed in both gilthead seabream and European seabass differ slightly. The tissue-specific expression pattern of Brdt seems to denote a different role in male and female gametogenesis of both fish species, although it may be that in the gonochoric fish species, European seabass ${ }^{4}$ Brdt plays a more important role as a key during female gametogeneis than in gilthead seabream, which is a protandrous hermaphroditic fish species with a bisexual gonad containing both spermatogonia and oogonia stem cells. ${ }^{41}$

A more exhaustive functional role of $B r d t$ gene could be demonstrated by complementary analysis in parallel by using some molecular, cellular and physiological approaches, such as studies on variation patterns during the annual reproductive cycles in both males and females, as well as during sex determinationdifferentiation developmental stages in juveniles of both fish species.

\section{References}

1. Bagni M. Cultured Aquatic Species Information Programme. Dicentrarchus labrax [updated 2005 Feb 18; cited 2016 Feb 12]. In: FA0 Fisheries and Aquaculture Department [online]. Rome, Italy.

2. Colloca F, Cerasi S. Aquatic Species Information Programme. Sparus aurata [updated 2005 Feb 8; cited 2016 Feb 12] In: FAO Fisheries and Aquaculture Department [online]. Rome, Italy.

3. Devlin R, Nagahama Y. Sex determination and sex differentiation in fish: an overview of genetic, physiological, and environmental influences. Aquaculture 2002;208:191-364.

4. Piferrer F, Blázquez M, Navarro L, González A. Genetic, endocrine, and environmental components of sex determination and differentiation in the European sea bass (Dicentrarchus labrax L.). Gen Comp Endocrinol 2005; 42:102-10.

5. Chaves-Pozo E, Mulero V, Meseguer J, García-Ayala A. An overview of cell renewal in the testis throughout the reproductive cycle of a seasonal breeding teleost, the gilthead seabream (Sparus aurata L). Biol Reprod 2004;72:593-601.

6. Piferrer F, Guiguen Y. Fish gonadogenesis. Part II: molecular biology and genomics of sex differentiation. Rev Fish Sci 2008;16: 35-5.
7. Martínez P, Viñas AM, Sánchez L, Díaz N, Ribas L, Piferrer F. Genetic architecture of sex determination in fish: applications to sex ratio control in aquaculture. Front Genet 2014;5:340.

8. Berkovits BD, Wolgemuth DJ. The role of the double bromodomain-containing BET genes during mammalian spermatogenesis. Curr Top Dev Biol 2013;102:293-326.

9. Jones MH, Numata M, Shimane M. Identification and characterization of BRDT: A testis-specific gene related to the bromodomain genes RING3 and Drosophila fish. Genomics 1997;45:52934.

10. Airoldi CA, Rovere FD, Falasca G, Marino G, Kooiker M, Altamura MM, Citterio S, Kater MM. The Arabidopsis BET bromodomain factor GTE4 is involved in maintenance of the mitotic cell cycle during plant development. Plant Physiol 2010;152:132034.

11. Florence B, Faller DV. You bet-cha: a novel family of transcriptional regulators. Front Biosci 2001;6:D1008-18.

12. Delcuve GP, Rastegar M, Davie JR. Epigenetic control. J Cell Physiol 2009; 219:243-50.

13. Pivot-Pajot C, Caron C, Govin J, Vion A, Rousseaux S, Khochbin, S. Acetylationdependent chromatin reorganization by BRDT, a testis-specific bromodomain-containing protein. Mol Cell Biol 2003;23: 5354-65.

14. Shang E, Salazar G, Crowley TE, Wang X, Lopez RA, Wang $X$, et al. Identification of unique, differentiation stage-specific patterns of expression of the bromodomaincontaining genes Brd2, Brd3, Brd4, and Brdt in the mouse testis. Gene Expr Patterns 2004;4:513-9.

15. Berkovits BD, Wolgemuth DJ. The first bromodomain of the testis-specific double bromodomain protein Brdt is required for chromocenter organization that is modulated by genetic background. Dev Biol 2011;360:358-68.

16. Shang E, Nickerson HD, Wen D, Wang X, Wolgemuth DJ. The first bromodomain of Brdt, a testis-specific member of the BET sub-family of double-bromodomain-containing proteins, is essential for male germ cell differentiation. Development 2007;134:3507-15.

17. Morinière J, Rousseaux S, Steuerwald U, Soler-López M, Curtet S, Vitte AL et al. Cooperative binding of two acetylation marks on a histone tail by a single bromodomain. Nature 2009;461:664-8.

18. Berkovits BD, Wang L, Guarnieri P, Wolgemuth DJ. The testis-specific double bromodomain-containing protein BRDT forms a complex with multiple spliceo- 
some components and is required for mRNA splicing and 3'-UTR truncation in round spermatids. Nucleic Acids Res 2012;40:7162-75.

19. Gaucher J, Boussouar F, Montellier E, Curtet S, Buchou T, Bertrand S, et al. Bromodomain-dependent stage-specific male genome programming by Brdt. EMBO. 2012;31:3809-20.

20. Chua P, Roeder GS. Bdf1, a yeast chromosomal protein required for sporulation. Mol Cell Biol 1995;15:3685-96.

21. Bošković A, Torres-Padilla ME. How mammals pack their sperm: a variant matter. Genes Dev 2013;27:1635-9.

22. Úbeda-Manzanaro M, Merlo MA, OrtizDelgado JB, Rebordinos L, Sarasquete C. Expression profiling of the sex-related gene Dmrtl in adults of the Lusitanian toadfish Halobatrachus didactylus (Bloch and Schneider, 1801). Gene 2014;535:255-65.

23. Kalendar R, Lee D, Schulman AH. FastPCR software for PCR primer and probe design and repeat search. Genes Genom Genomics 2009;3:1-14.

24. Hall TA. BioEdit: a user-friendly biological sequence alignment editor and analysis program for Windows 95/98/NT. Nucleic Acids Symp Ser 1999;41:95-8.

25. Saitou N, Nei, M. The neighbour-joining method: a new method for reconstructing phylogenetic trees. Mol Biol Evol 1987;4: 406-25.

26. Tamura K, Stecher G, Peterson D, Filipski A, Kumar S. MEGA6: molecular evolutionary genetics analysis version 6.0 . Mol Biol Evol 2013;30:2725-9.

27. Felsenstein J. Confidence limits on phylogenies: an approach using the bootstrap.
Evolution 1985;39:783-91.

28. Zuckerkandl E, Pauling L. 1965. Evolutionary divergence and convergence in proteins. In: Bryson V, Vogel HJ, editors. Evolving Genes and Proteins. New York: Academic Press. p 97-166.

29. Pfaffl MW. A new mathematical model for relative quantification in real-time RTPCR. Nucleic Acids Res 2001;29:e45.

30. Mohammed-Geba K, Mancera JM, Martínez-Rodríguez G. Acclimation to different environmental salinities induces molecular endocrine changes in the GH/IGF-I axis of juvenile gilthead sea bream (Sparus aurata L.). J Comp Physiol B 2015;185:87-101.

31. Martos-Sitcha JA, Gregório SF, Carvalho ES, Canario AV, Power DM, Mancera JM, et al. AVT is involved in the regulation of ion transport in the intestine of the sea bream (Sparus aurata). Gen Comp Endocrinol 2013;193:221-8.

32. Mitter K, Kotoulas G, Magoulas A, Mulero V, Sepulcre P, Figueras A, et al. Evaluation of candidate reference genes for qPCR during ontogenesis and of immune-relevant tissues of European seabass (Dicentrarchus labrax). Comp Biochem Physiol B Biochem Mol Biol 2009;153:3407.

33. Wu SY, Chiang CM. The double bromodomain-containing chromatin adaptor Brd4 and transcriptional regulation. $\mathrm{J}$ Biol Chem 2007;282:13141-5.

34. Paillisson A, Levasseur A, Gouret P, Callebaut I, Bontoux M, Pontarotti P, et al. Bromodomain testis-specific protein is expressed in mouse oocyte and evolves faster than its ubiquitously expressed par- alogs BRD2, -3, and -4 . Genomics 2007;89:215-23.

35. Zheng Y, Yuan W, Zhou Z, Xu M, Sha JH. Molecular cloning and expression of a novel alternative splice variant of BRDT gene. Int J Mol Med 2005;15:315-21.

36. Bisgrove DA, Mahmoudi T, Henklein P, Verdin, E. Conserved P-TEFb-interacting domain of BRD4 inhibits HIV transcription. P Natl Acad Sci USA 2007;104:136905.

37. Torgerson DG, Kulathinal, RJ, Singh RS. Mammalian sperm proteins are rapidly evolving: evidence of positive selection in functionally diverse genes. Mol Biol Evol 2002;19:1973-80.

38. Taniguchi Y, Suzuki H, Ohtsuka M, Kikuchi N, Kimura M, Inoko H. Isolation and characterization of three genes paralogous to mouse Ring3. Nucleic Acids Res Suppl 2001;1:247-8.

39. Barda S, Paz G, Yogev L, Yavetz H, Lehavi 0, Hauser R, et al. Expression of BET genes in testis of men with different spermatogenic impairments. Fertil Steril 2012;97:46-52.e5.

40. Kurtz K, Saperas N, Ausió J, Chiva M. Spermiogenic nuclear protein transitions and chromatin condensation. Proposal for an ancestral model of nuclear spermiogenesis. J Exp Zool B Mol Dev Evol 2009;312B: 149-63.

41. Franch R, Louro B, Tsalavouta M, Chatziplis D, Tsigenopoulos CS, Sarropoulou E, et al. A genetic linkage map of the hermaphrodite teleost fish Sparus aurata L. Genetics 2006;174:851-61. 